\title{
Intradiploic epidermoid cyst of the skull
}

\author{
Subash Phuyal ${ }^{1}$, DM; Kapil Dawadi ${ }^{1}$, MD; Rupendra Bahadur Adhikari ${ }^{2}$, MD, PhD \\ ${ }^{1}$ Department of Radiology and Imaging, Grande International Hospital, Kathmandu, Nepal \\ ${ }^{2}$ Department of Neurosciences - Neurosurgery, Grande International Hospital, Kathmandu, Nepal
}

\section{Corresponding author}

Subash Phuyal, MD, DM

Email: drsphuyal17@gmail.com

Received 31 Jul 2019

Accepted 17 Aug 2019

\section{Summary}

A 46 years old female, presented with a history of chronic headache, mainly on the left occipital region, which had increased in severity and frequency recently. Patient had no neurological deficits. Contrast enhanced computed tomography revealed large expansile non-enhancing intradiploic hypodense lesion within the squamous part of left side of occipital bone (Fig. a,b). Magnetic resonance image revealed non enhancing lesion with heterogeneous hyperintense matrix. Diffusion weighted imaging and apparent diffusion coefficient revealed intense diffusion restriction which confirms the nature of the tumor (Fig. c,d,e,f,g).

Epidermoid cysts are benign, slow-growing lesions and may often reach an enormous size without producing neurological symptoms. Less than $1 \%$ of cranial tumors are epidermoid tumours, of which $75 \%$ are intradural and $25 \%$ are intradiploic in location ${ }^{1}$. Intraparenchymal extension of intradiploic epidermoids is known to occur. Both CT and MR imaging modalities enable the preoperative diagnosis of these tumors with good accuracy. CT is superior for assessment of density of lesion, extent of involvement of the inner and outer tables and presence of calcification ${ }^{2}$. MRI is superior to CT in demonstrating lesions that have associated parenchymal involvement and lesions that do not have associated bone destruction ${ }^{3}$.

\section{References}

1. Arana E, Latorre FF, Revert A, Menor F, Riesgo $P$, Liano $F$, et al. Intradiploic epidermoid cysts. Neuroradiology 1996;38:306-11.

2. Guiard JM, Kien P, Colombani S, Caillé JM. Intradiploicepidermoides cysts in adults. CT contribution to diagnosis in 6 new cases. J Neuroradiol 1986;13;22-31.

3. Olson J, Back D, Cranford S, Menezes A. Comparative evaluation of intra cranial epidermoid tumors with computed tomography and magnetic resonance imaging. Neurosurgery 1987;21:357- 60. 


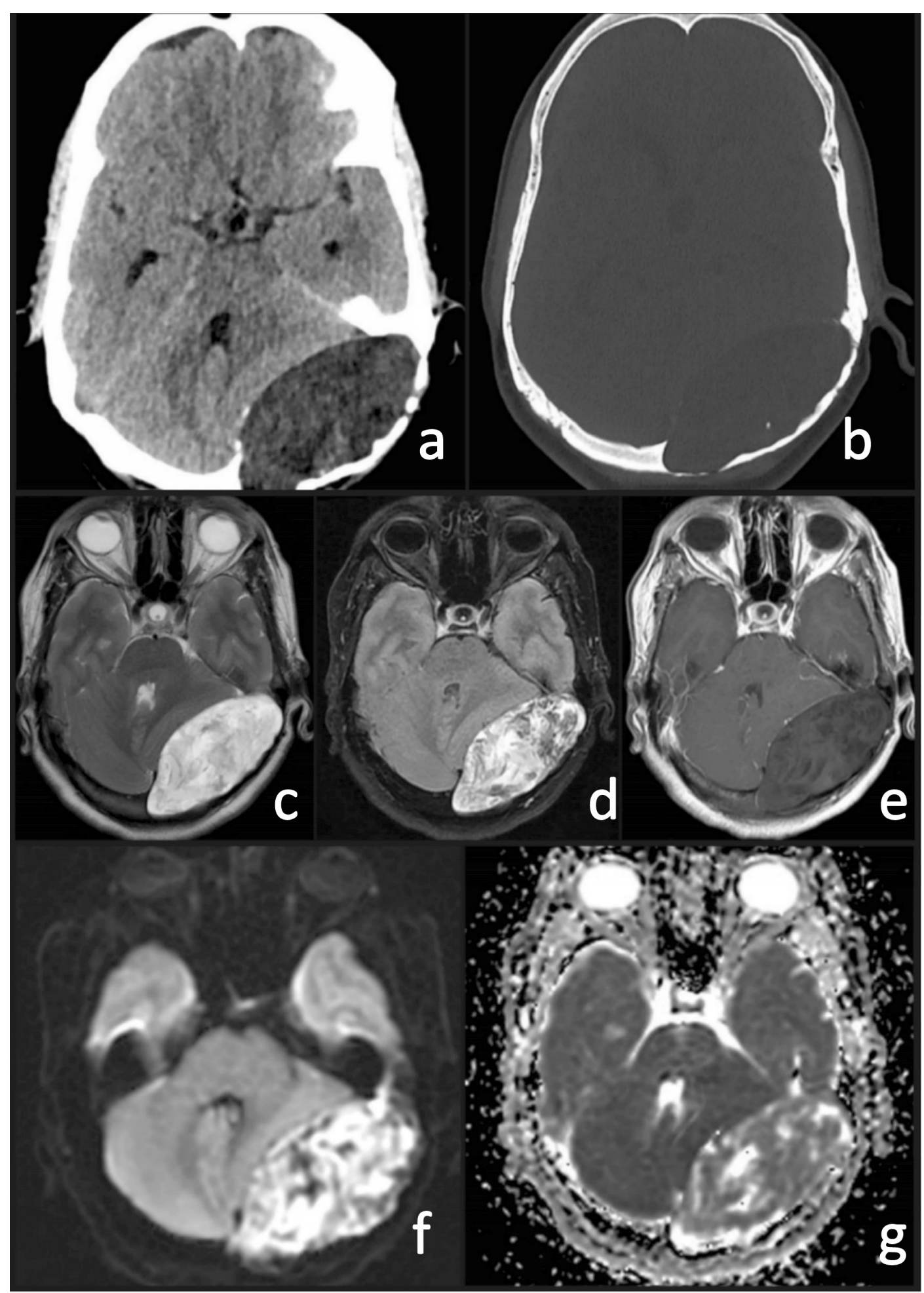

Figure Index

Fig. a: Axial soft tissue window contrast enhanced CT showing large expansile non-enhancing hypodense lesion within the squamous part of left side occipital bone. The underlying left cerebellar hemisphere is compressed

Fig. b: Axial bone window CT showing thinning of inner and outer tables by the lesion and few intralesional calcific foci (white arrow).

Fig. c; d: Axial T2W and FLAIR MR imaging showing heterogeneous hyperintense matrix with no abnormal signal in adjacent parenchyma.

Fig. e: Axial post-contrast T1W MR imaging showing no enhancement of the lesion.

Fig. f; g: Axial DWI and ADC sequences showing intense restriction. 